\title{
Cell-Penetrating Peptides as a Tool for the Cellular Uptake of a Genetically Modified Nitroreductase for use in Directed Enzyme Prodrug Therapy
}

\author{
Simon D. Anderson ${ }^{1}{ }^{\oplus}$, Robert J. Hobbs ${ }^{1} \oplus$, Vanessa V. Gwenin ${ }^{1}$, Patrick Ball ${ }^{1}$, \\ Lindsey A. Bennie ${ }^{2}$, Jonathan A. Coulter ${ }^{2}$ and Chris D. Gwenin ${ }^{1, *(\mathbb{C}}$ \\ 1 School of Natural Sciences, Bangor University, Bangor, Gwynedd, Wales LL57 2DG, UK; \\ s.anderson@bangor.ac.uk (S.D.A.); r.j.hobbs@bangor.ac.uk (R.J.H.); v.gwenin@bangor.ac.uk (V.V.G.); \\ chp60c@bangor.ac.uk (P.B.) \\ 2 School of Pharmacy, Queen's University Belfast, Belfast BT7 1NN, UK; lbennie01@qub.ac.uk (L.A.B.); \\ j.coulter@qub.ac.uk (J.A.C.) \\ * Correspondence: c.d.gwenin@bangor.ac.uk; Tel.: +44-01248-38-3741
}

Received: 16 August 2019; Accepted: 30 September 2019; Published: 1 October 2019

\begin{abstract}
Directed enzyme prodrug therapy (DEPT) involves the delivery of a prodrug-activating enzyme to a solid tumour site, followed by the subsequent activation of an administered prodrug. One of the most studied enzyme-prodrug combinations is the nitroreductase from Escherichia coli (NfnB) with the prodrug CB1954 [5-(aziridin-1-yl)-2,4-dinitro-benzamide]. One of the major issues faced by DEPT is the ability to successfully internalize the enzyme into the target cells. NfnB has previously been genetically modified to contain cysteine residues (NfnB-Cys) which bind to gold nanoparticles for a novel DEPT therapy called magnetic nanoparticle directed enzyme prodrug therapy (MNDEPT). One cellular internalisation method is the use of cell-penetrating peptides (CPPs), which aid cellular internalization of cargo. Here the cell-penetrating peptides: HR9 and Pep-1 were tested for their ability to conjugate with NfnB-Cys. The conjugates were further tested for their potential use in MNDEPT, as well as conjugating with the delivery vector intended for use in MNDEPT and tested for the vectors capability to penetrate into cells.
\end{abstract}

Keywords: nitroreductase; cell-penetrating peptide; prodrug therapy; darkfield imaging; nanoparticle

\section{Introduction}

The ability of materials to traverse the cell membrane is an important factor that has to be taken into consideration when devising new medical treatments, requiring careful engineering to aid in target cell uptake [1]. One of the most common forms of cell internalisation for molecular cargoes is endocytosis. This process generally involves the formation of a vesicle surrounding the cargo, which is then engulfed into the cell [2]. However, contents within the vesicle/endosome are often moved into the endo-lysosomal system and are digested by acid hydrolases [3], rendering the cargo unusable for its desired function. While this process is ideal for the uptake of nutrients and for the protection of cells from antigens and toxins [4], it places a restriction on the therapeutic potential of novel therapies. As such, it is important to discover novel approaches to efficiently enable target cell uptake, for which cell-penetrating peptides (CPPs) represent one solution. CPPs are short peptides [5], often no more than 30 amino acids in length [6]. Some CPPs possess the ability to pass through the cell membrane and bypass the endosomal system, leaving cargoes intact [7]. It is often reported that there are several properties that CPPs possess which enable them to efficiently pass into cells including being rich in arginine and/or tryptophan residues [8-10] and possessing an overall positive charge at physiological $\mathrm{pH}$ ( 7.4) [10]. CPPs have already been shown to deliver a wide range of cargo into cells, including nucleic acids [11], proteins [12], and nanoparticles [13]. 
Directed enzyme prodrug therapy (DEPT) has previously been explored as an emerging form of cancer treatment [14-20]. DEPT involves the delivery of a prodrug activating enzyme to a solid tumour site, whereby after cell internalisation of the enzyme, a prodrug is then administered. One of the most studied nitroreductase-prodrug combinations is nitroreductase from Escherichia coli (NfnB) $\mathrm{K}-12$, used in combination with the prodrug; CB1954 (5-(aziridine-1-yl)-2,4-dinitrobenzene). NfnB converts CB1954 into either of the toxic 2'- or 4'-hydroxylamine derivatives, with this combination having had a previous promising clinical outcome [21]. A range of strategies has been investigated to directly deliver the enzyme or the encoding DNA to the target site, including viruses (VDEPT) [22,23], antibodies (ADEPT) [24], peptides [25], and cationic lipids [26]. We have investigated a novel form of DEPT that involves the incorporation of gold-coated superparamagnetic iron oxide nanoparticles (AuMNP) as the delivery vehicle used to direct the enzyme to the tumour site, an approach termed magnetic nanoparticle directed enzyme prodrug therapy (MNDEPT) [14,27]. A genetically modified nitroreductase (NfnB-Cys) is conjugated to the surface of the nanoparticles $[14,28]$ with conjugates already proven to retain their prodrug reducing capability [29].

However, it has not yet been established whether the NfnB-Cys enzyme could be conjugated to a CPP to enhance target cell uptake while retaining the reduction activity of CB1954. For these experiments, two CPPs were chosen (HR9 and Pep-1) for conjugation to NfnB-Cys to assess cellular uptake. Both CPPs have been shown to conjugate to peptides and protein structures, improving internalization [30-33]. It was anticipated that the same improved internalization effect would be seen with NfnB-Cys. The aims of this work were to assess conjugation of the CPPs onto NfnB-Cys, and what effects this had on the enzymes activity and ability to reduce the CB1954 prodrug and cause cell death. Further to this was to conjugate NfnB-Cys and the CPPs onto magnetic nanoparticles intended for use in MNDEPT and again test for the ability for the NfnB-Cys to reduce CB1954 causing cell death.

\section{Results}

\subsection{NfnB-Cys Expression and Purification}

The NfnB enzyme is native to E. coli, but has been genetically modified by our research group to contain six Cys-tags on the N-terminus of the protein [14]. The six Cys-tags aid the in the covalent binding of the NfnB-Cys onto gold nanoparticles $[14,28]$. The gene was cloned into the pET28a(+) vector, which added an additional six histidine residues after the Cys-tag for downstream purification of the protein using metal ion affinity chromatography (IMAC). The SDS-PAGE gel of the purification is presented in Figure 1, where the NfnB-Cys enzyme, eluted strongly between 300-800 mM imidazole, with the highest concentration being the $500 \mathrm{mM}$ fraction. Due to the high concentration of protein, both monomeric and dimeric units were seen at $27.3 \mathrm{kDa}$ and $54.6 \mathrm{kDa}$. The NfnB-Cys enzyme was obtained at a yield of up to $5 \mathrm{mg} / \mathrm{mL}$. 


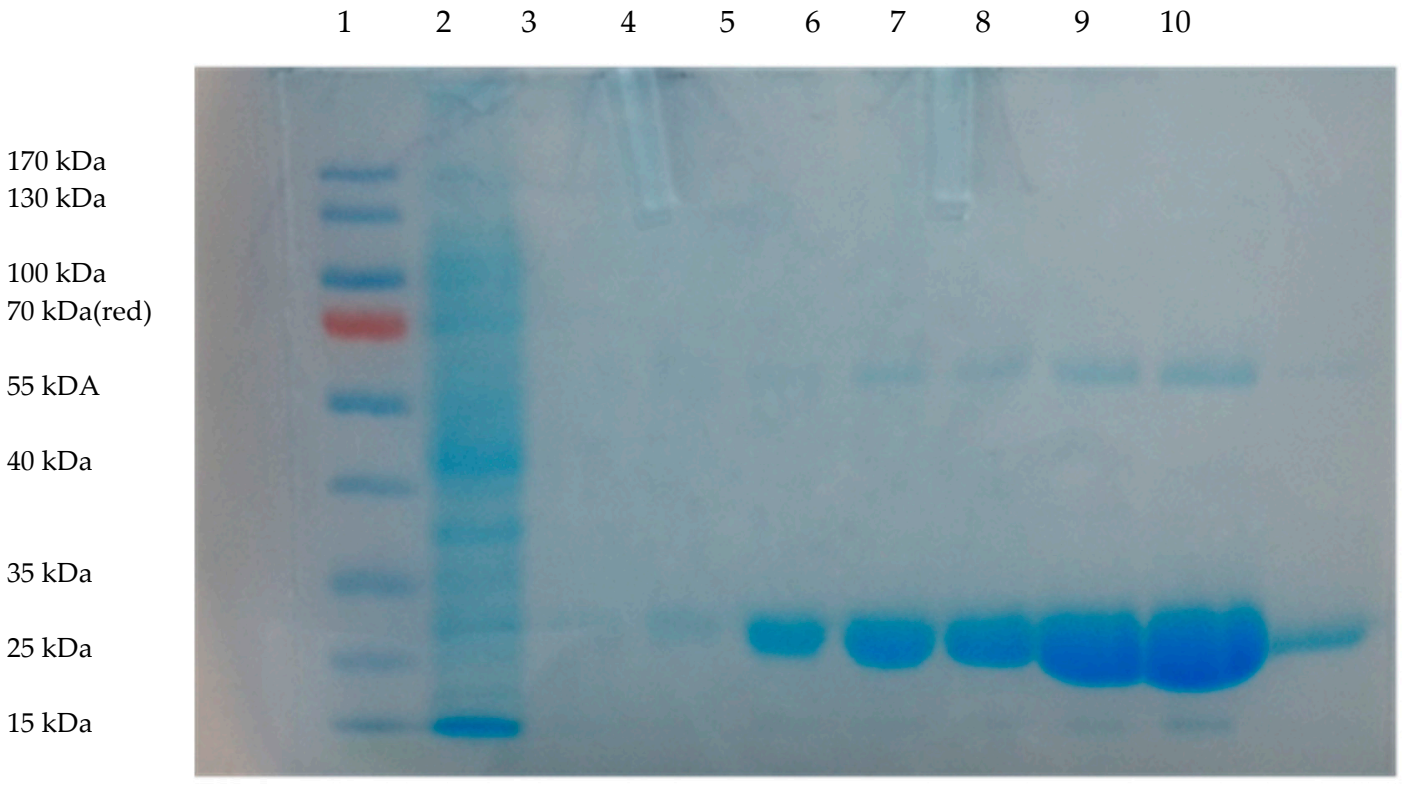

Figure 1. SDS-PAGE gel of the genetically modified nitroreductase (NfnB-Cys) purification using metal ion affinity chromatography (IMAC): lane 1, protein ladder (Thermoscientific PageRuler 15-170 kDa); lane 2, flow-through after applying supernatant to column; lane 3, flow-through after applying $10 \mathrm{mM}$ imidazole to column; lane 4, $50 \mathrm{mM}$ imidazole eluent; lane 5, $100 \mathrm{mM}$ imidazole eluent; lane 6, $200 \mathrm{mM}$ imidazole eluent; lane 7, $300 \mathrm{mM}$ imidazole eluent; lane 8, $500 \mathrm{mM}$ imidazole eluent; lane 9, $800 \mathrm{mM}$ imidazole eluent; lane 10, $1000 \mathrm{mM}$ imidazole eluent.

\subsection{Conjugation of HR9 and Pep-1 to NfnB-Cys}

CPPs can be non-covalently conjugated to a wide range of materials $[30,32-38]$. One of the aims of this work was to attempt to improve the cellular uptake of the NfnB-Cys into cells, conjugation of CPPs onto the NfnB-Cys could aid in this process. CPPs were conjugated onto the NfnB-Cys at varying ratios. A further aim is to conjugate the NfnB-Cys onto AuMNPs which act as the delivery vector for our DEPT method, however, it needed to be established if the CPPs could interact with the NfnB-Cys without causing any negative effect. To look for proof of binding of the CPPs HR9 and Pep-1 to NfnB-Cys, native agarose (1\%) gels were performed, with images of the stained gels shown in Figure 2 with the free NfnB-Cys, free CPP, and NfnB-Cys:CPP conjugate migration through the gels being analysed. A common feature of many CPPs is their cationic charge, therefore if the CPPs bind to the NfnB-Cys, the charge will differ from that of free NfnB-Cys, with the conjugates differently migrating through the agarose gel. As seen in Figure 2A, HR9 is positively charged, shown by migration towards the anode, whilst free NfnB-Cys is negative, shown by migration towards the cathode. Migration of the NfnB-cys-HR9 conjugates is retarded through the gel resulting in a streaked pattern. Similarly, as seen in Figure 2B, the Pep-1 CPP is also positively charged and migrates to the anode, whilst the NfnB-Cys:Pep-1 conjugates, are again retarded through the gel, particularly at higher Pep-1 ratios (1:5, 1:10, and 1:15). A similar effect can be seen in the 1:15 ratio of NfnB-Cys conjugated with HR9, although it is not as pronounced as the effect seen with Pep-1. 


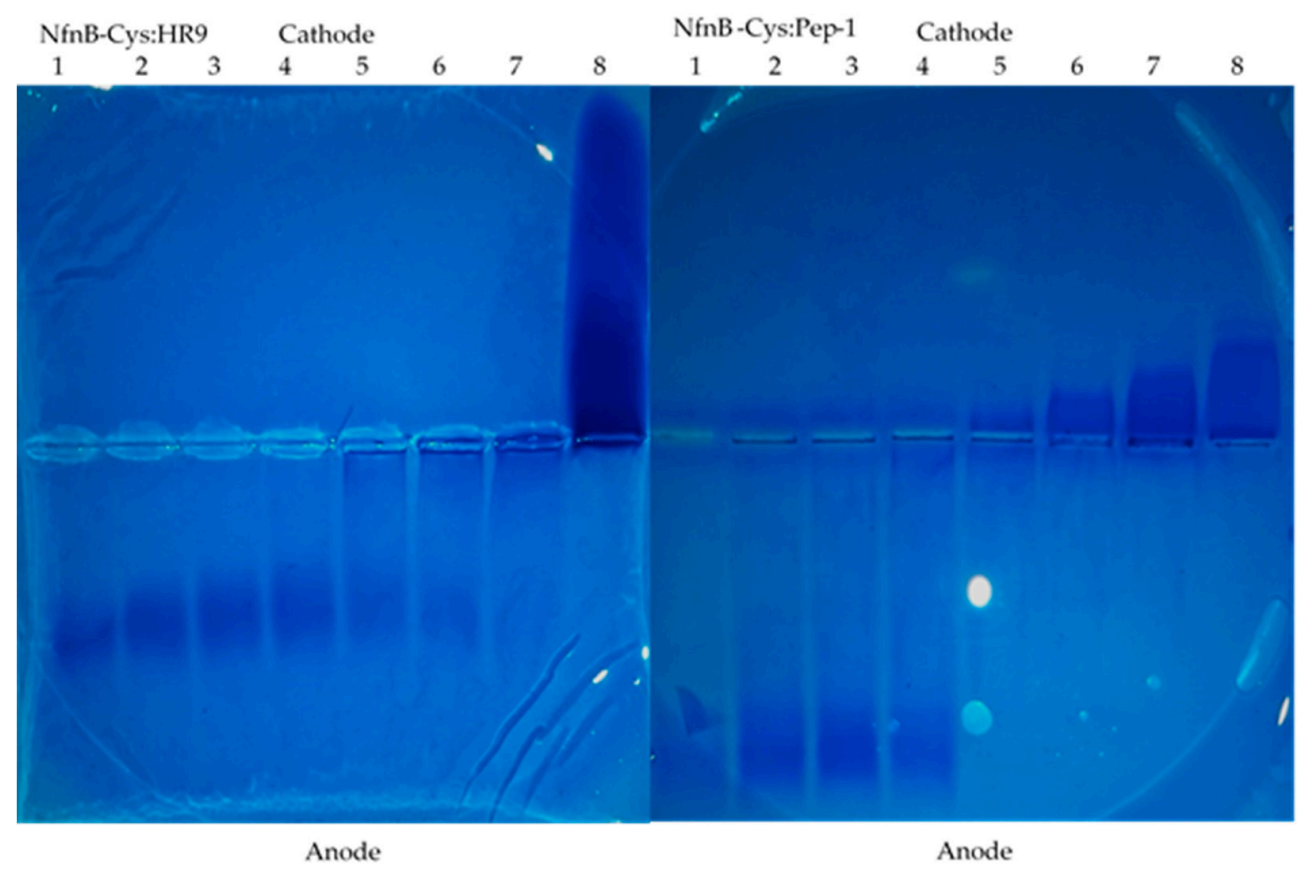

(A)

(B)

Figure 2. Agarose gels of the NfnB-Cys enzyme conjugated with HR9 (A) and Pep-1 (B). Gels have unconjugated NfnB-Cys in lane 1, increasing ratios of NfnB-Cys:cell-penetrating peptides (CPPs) in lanes $2,3,4,5,6$, and 7 of 1:0.1, 1:0.2, 1:1, 1:5, 1:10, and 1:15 respectively, and unconjugated CPP in the lane 8 .

\subsection{NfnB-Cys and NfnB-Cys:CPP Conjugate Reactivity to CB1954}

The genetically modified NfnB-Cys enzyme reactivity towards the prodrug CB1954 has previously reported by Gwenin et al. [14,39]. The addition of a Cys-tag was shown not to negatively affect enzymatic activity [28], but the conjugation of the CPPs onto the NfnB-Cys may influence enzyme reactivity towards CB1954. For this reason, NfnB-Cys:CPP conjugates were analysed for their CB1954 reactivity and compared relative to the free NfnB-Cys enzyme, the data for which is presented in Figure 3.

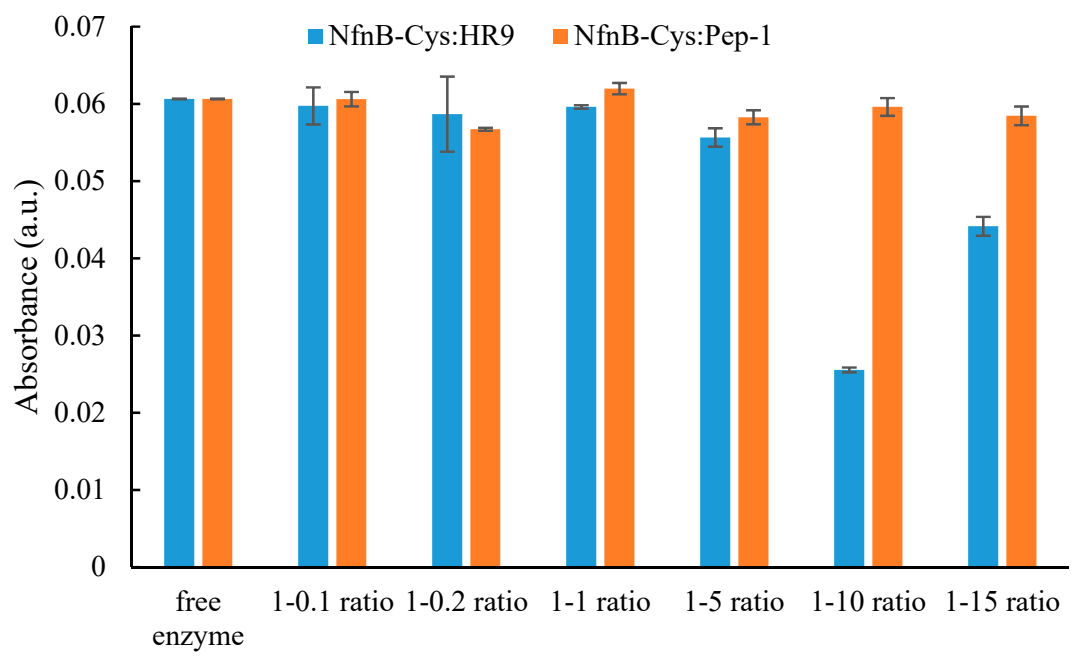

Figure 3. The change in absorbance at $420 \mathrm{~nm}$ over $15 \mathrm{~min}$ for NfnB-Cys conjugated with varying ratios of HR9 (blue) or Pep-1 (orange) (wt:wt). The reactions were carried out in the presence of NADH $(1200 \mu \mathrm{M})$ and CB1954 (1000 $\mu \mathrm{M})$. 
When NfnB-Cys was conjugated with HR9 at varying ratios, hydroxylamine product formation could still be seen at $420 \mathrm{~nm}$, however, there appeared to be a significant effect on product formation at ratios above 1:1. The experiment was repeated for NfnB-Cys:Pep-1 conjugates and no major effect on product formation was seen for all ratios tested. Kinetic parameters were then determined by generating a Michaelis-Menten profile for the conjugates (Table 1).

Table 1. Michaelis-Menten kinetic data obtained for NfnB-Cys and the conjugated NfnB-Cys with HR9 and Pep-1 by varying the concentrations of the CB1954 prodrug in the presence of NADH as the cofactor.

\begin{tabular}{ccccc}
\hline Conjugate & $\mathbf{V}_{\max }\left(\boldsymbol{\mu} \mathbf{M s}^{-\mathbf{1}}\right)$ & $\mathbf{K}_{\text {cat }}\left(\mathbf{s}^{-\mathbf{1}}\right)$ & $\mathbf{K}_{\mathbf{m}}(\boldsymbol{\mu M})$ & $\mathbf{K}_{\text {cat }} / \mathbf{K}_{\mathbf{m}}\left(\boldsymbol{\mu} \mathbf{M}^{-\mathbf{1}} \mathbf{s}^{-\mathbf{1}}\right)$ \\
\hline NfnB-Cys:HR9 & $7.98 \pm 1.39$ & $9.06 \pm 0.82$ & $3443 \pm 916$ & $0.00263 \pm 4.6 \times 10^{4}$ \\
NfnB-Cys:Pep-1 & $7.43 \pm 1.25$ & $8.44 \pm 0.73$ & $2381 \pm 695$ & $0.00354 \pm 6.5 \times 10^{4}$ \\
\hline
\end{tabular}

The comparison of the NfnB-Cys:CPP conjugates with our previously reported free NfnB-Cys enzyme kinetics [29] and indicated an alteration in the enzyme's kinetic behaviour, for both NfnB-Cys:CPP conjugates. The $\mathrm{k}_{\mathrm{cat}}$ and $\mathrm{K}_{\mathrm{m}}$ values presented are the apparent (app) values measured at $400 \mu \mathrm{M}$ NADH. The CPPs decreased efficiency of NfnB-Cys; $\mathrm{k}_{\mathrm{cat}} / \mathrm{K}_{\mathrm{m}}=0.0026 \mu \mathrm{M}^{-1} \mathrm{~s}^{-1}$ for NfnB-Cys:HR9 and $0.0033 \mu \mathrm{M}^{-1} \mathrm{~s}^{-1}$ for NfnB-Cys:Pep-1, compared to $\mathrm{k}_{\text {cat }} / \mathrm{K}_{\mathrm{m}}=0.011 \mu \mathrm{M}^{-1} \mathrm{~s}^{-1}$ for NfnB-Cys). The reaction parameters had to be modified to use a higher concentration of NfnB-Cys:HR9/Pep-1 to obtain full kinetic profiles of the conjugates, due to prodrug cost, therefore only the $\mathrm{k}_{\mathrm{cat}} / \mathrm{K}_{\mathrm{m}}$ constant can be directly compared between the NfnB-Cys enzyme and the NfnB-Cys:CPP conjugates. In comparison the NfnB-Cys:HR9 shows a slightly higher product turnover compared to the NfnB-Cys:Pep-1conjugate $\left(k_{\text {cat }}(\right.$ app $)=9.1 \mathrm{~s}^{-1}$ and $8.4 \mathrm{~s}^{-1}$ respectively), however, the NfnB-Cys:Pep-1 demonstrates a higher affinity than NfnB-Cys:HR9 for the CB1954 $\left(\mathrm{K}_{\mathrm{m}}(\mathrm{app})=2400 \mu \mathrm{M}\right.$ and $3400 \mu \mathrm{M}$ respectively). These results show that when conjugated to the CPPs; HR9 and Pep-1 at a 1:1 ratio NfnB-Cys has a $65-74 \%$ decrease in kinetic efficiency. These results are presented in Table 1.

\subsection{HPLC Profiles of NfnB-Cys and NfnB-Cyse:CPP Reaction Products}

Previously we have shown that after a $30 \mathrm{~min}$ reaction time, NfnB-Cys reduced CB1954 to two products (namely 2-NHOH and 4-NHOH) at a ratio of 32:68 respectively [29]. Following the same procedure, conjugates of NfnB-Cys and the CPPs at a 1:1 molar ratio were tested for their ability to reduce CB1954. Reaction product ratios were established, with the 4-NHOH product eluting at approximately $5 \mathrm{~min}$ and the 2-NHOH eluting at $10 \mathrm{~min}[29,39]$. The product ratios obtained for the reactions between NfnB-Cys:CPP conjugates and CB1954 are presented in Table 2; the NfnB-Cys:HR9 produced products at a ratio of 36:64 (2'-NHOH vs 4'-NHOH), whilst the NfnB-Cys:Pep-1 produces the 2-NHOH and 4-NHOH at a ratio of 35:65.

Table 2. The ratio of the CB1954 hydroxylamine derivatives formed when NfnB-Cys:CPP conjugates were reacted with CB1954 in the presence of NADH as determined by HPLC.

\begin{tabular}{cc}
\hline Conjugate & Ratio (2-NHOH:4-NHOH) \\
\hline NfnB-Cys:HR9 & $36: 64$ \\
NfnB-Cys:Pep-1 & $35: 65$ \\
\hline
\end{tabular}

\subsection{Effect of NfnB-Cys and NfnB-Cys:CPP Conjugate on Cell Viability}

Cell viability of SK-OV-3 cells presented as percentage cell survival was determined using an increasing concentration of NfnB-Cys and NfnB-Cys:CPP conjugate and a constant CB1954 concentration $(10 \mu \mathrm{M})$. Cells were incubated with medium, prodrug, and enzyme separately as controls. NfnB-Cys was tested for its ability to induce cell death by the reduction of CB1954. This combination showed an average cell viability of $80 \%$ at an NfnB-Cys treatment concentration of $200 \mathrm{nM}$, 
with the full results shown in Figure 4. Next, the NfnB-Cys:HR9 and NfnB-Cys:Pep-1 conjugates were also tested for their ability to cause cell death, and compared relative to free NfnB-Cys, again full results are displayed in Figure 4.

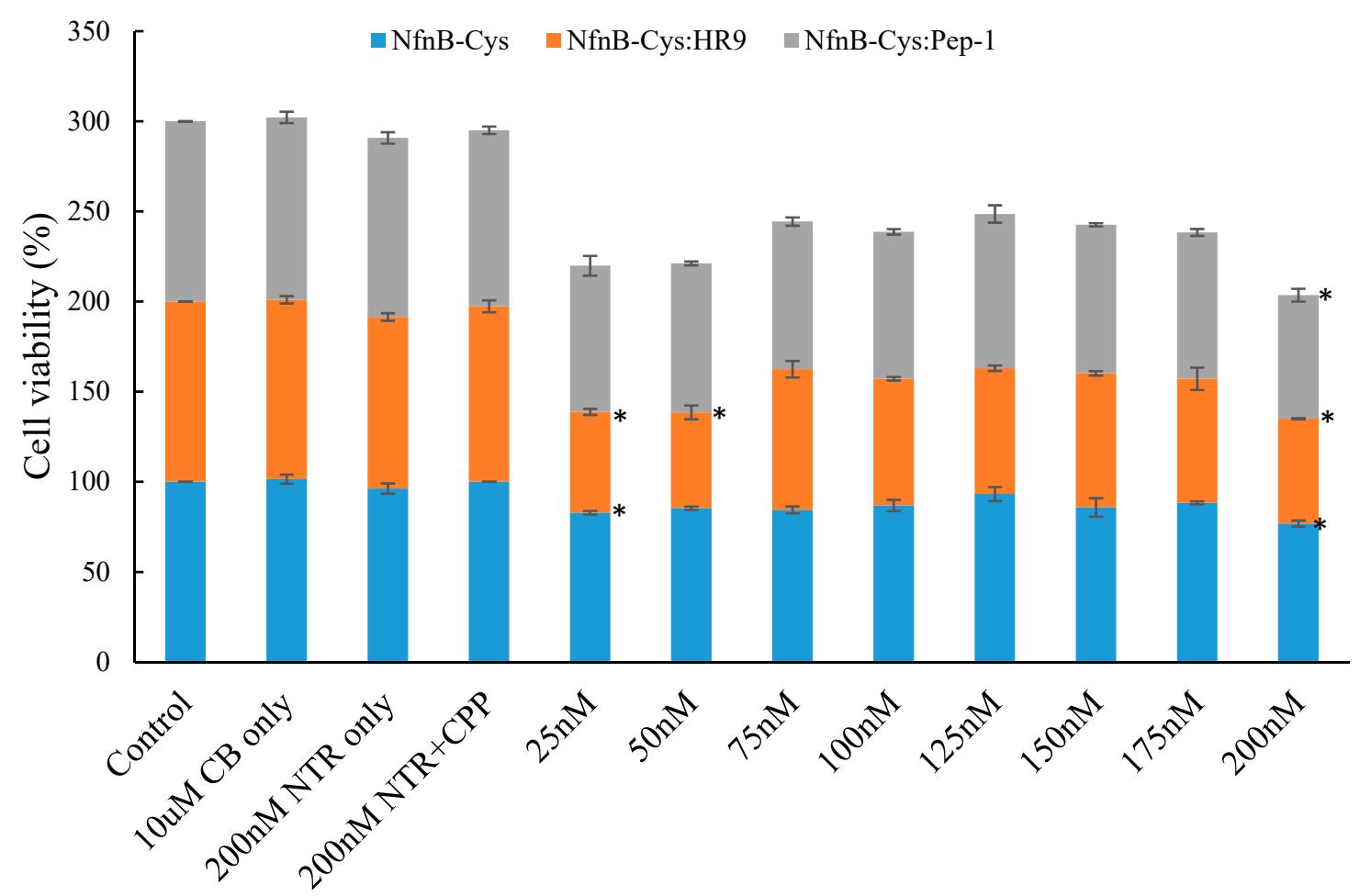

Figure 4. The percentage cell survival of SK-OV-3 cells after $4 \mathrm{~h}$ incubation with: cell culture medium only, $10 \mu \mathrm{M}$ CB1954 only, 200 nM NfnB-Cys only, 200 nM NfnB-Cys:CPP only, and increasing concentrations of either; NfnB-Cys (blue), NfnB-Cys:HR9 (orange), or NfnB-Cys:Pep-1 (grey) (25-200 nM) in the absence of NADH. Data points determined to be statistically significant by Dunnett test are marked with $\mathrm{a}^{*}$. All data points represent at least three repeats and error bars indicate \pm 1 standard deviation.

At each concentration tested, the NfnB-Cys:HR9 conjugates (25-200 nM) appear to be more effective at causing cell death compared to NfnB-Cys alone (on average by 15\%). Neither Pep-1 nor HR9 CPPs conferred any direct cytotoxicity towards SK-OV-3 cells. These results suggest that NfnB-Cys conjugates exhibited a greater endocytotic potential, because, as shown from the kinetic experiments, cell kill could not be attributed to enhanced enzyme efficiency. The data were analysed for statistical significance by F-test with all data sets demonstrating levels of statistical significance $(P<0.005)$, with the individual data points being analysed using the Dunnett test. Data points marked with a * exceeded the Dunnett critical value indicating statistical significance.

\subsection{Effect of AuMNPs and AuMNP Conjugates on Cell Viability}

NfnB-Cys has been shown to successfully conjugate onto AuNPs [14], therefore it was considered highly probable the same would be observed when conjugating onto AuMNPs. Conjugation of NfnB-Cys onto AuMNPs was assessed by UV-Vis, Figure 5 is the overlay of UV-Vis scans between 450 and $650 \mathrm{~nm}$. Here it is observed that post conjugation the $\lambda$-max of the gold peak has increased by $4 \mathrm{~nm}$ from 536 to $540 \mathrm{~nm}$, an indication of successful conjugation. 


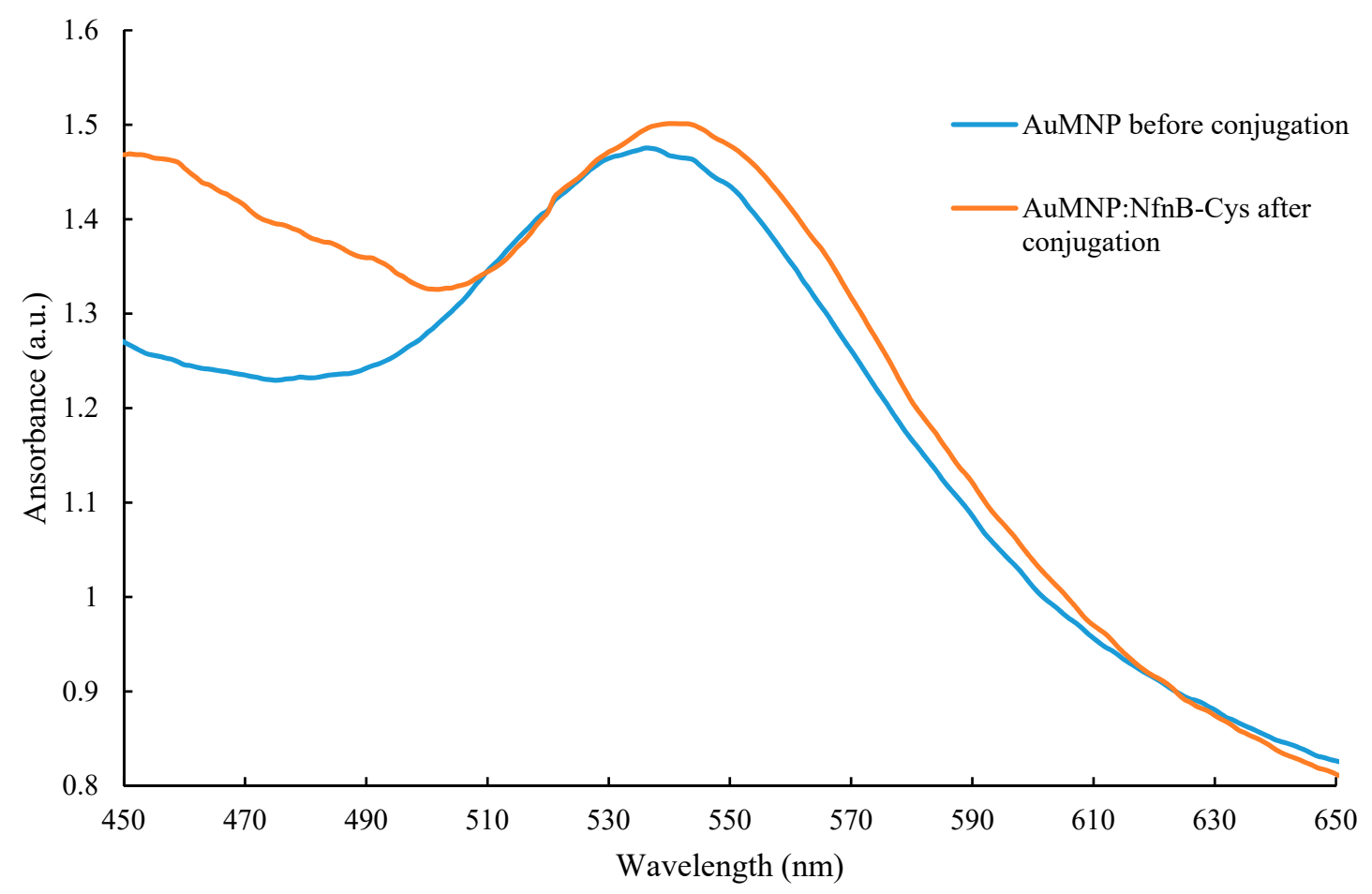

Figure 5. Full-spectrum (450-650 nm) UV-vis spectrum of gold-coated superparamagnetic iron oxide nanoparticles (AuMNPs) before (blue) and after (orange) conjugation with NfnB-Cys at a ratio of 1:270 of AuMNP:NfnB-Cys. Scans were taken $48 \mathrm{~h}$ apart.

There was a concern that, while performing the MTT assay on the AuMNPs, any exposed iron nanoparticles would cause excess oxidation of the MTT yielding a bias on the final cell viability percentage [40,41]. A brief experiment was performed to assess if the AuMNPs would cause excess oxidation of the MTT causing a result bias. The AuMNPs caused a large excess of oxidation of the MTT indicating a different cell culture assay would be required (data not shown). Due to this, the calcein assay was selected as it requires the use of cellular esterase's to convert calcein-AM into the fluorescent calcein, an initial test showed the AuMNPs are not able to reduce calcein-AM to calcein indicating the assay could be used without the risk of an experimental bias (data not shown). Figure 6 is the cell viability results of cells treated with: AuMNPs, AuMNP:NfnB-Cys, or AuMNP:NfnB-Cys:HR9, here the range of concentrations examined are the same as the cell viability experiments not containing AuMNPs that are described in Sections 2.5, 3 and 4.7.

The AuMNPs do not demonstrate any direct toxicity towards the SK-OV-3 cells. As expected, when AuMNP:NfnB-Cys and AuMNP:NfnB-Cys:HR9 conjugates were treated onto cells, there was cell kill, which was taken to be the NfnB-Cys reducing the CB1954 due to the lack of toxicity presented in the conjugated control samples. Here once again the conjugates with the HR9 do present a slightly better cell kill overall than the AuMNP:NfnB-Cys, however the increase in the cell kill is minimal at best. The data were analysed for statistical significance by F-test with all data sets demonstrating levels of statistical significance $(P<0.005)$. The Dunnett test could not be performed to determine individual data points statistical significance due to the low number of concentrations tested. 


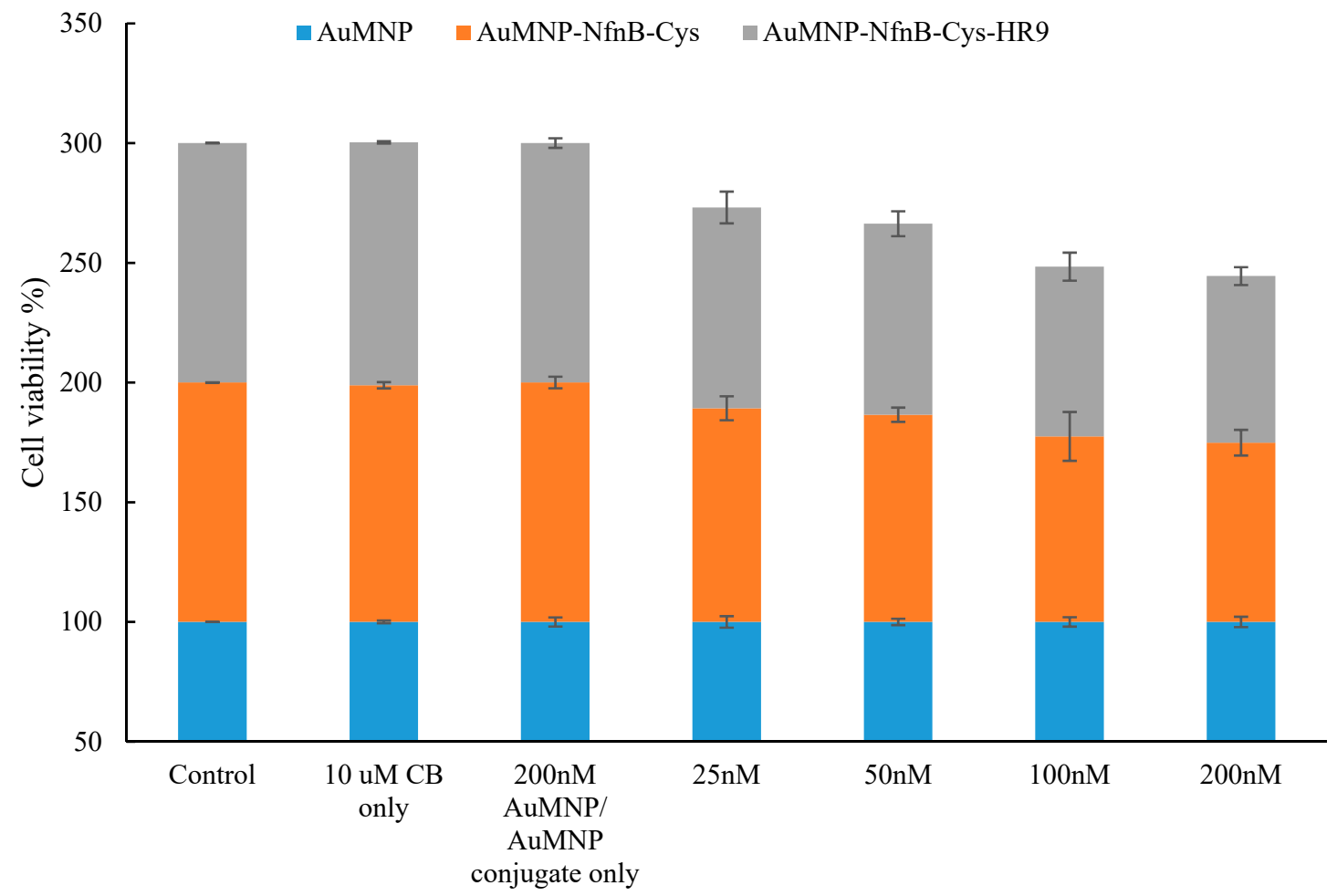

Figure 6. The percentage cell survival of SK-OV-3 cells after $4 \mathrm{~h}$ incubation with: cell culture medium only, $10 \mu \mathrm{M}$ CB1954 only, $200 \mathrm{nM}$ AuMNP only, $200 \mathrm{nM}$ AuMNP:NfnB-Cys only, or $200 \mathrm{nM}$ AuMNP:NfnB-Cys:CPP only as control wells. Reaction wells contained increasing concentrations of either; AuMNP (blue), AuMNP:NfnB-Cys (orange), or AuMNP:NfnB-Cys:HR9 (grey) (25-200 nM) in the absence of NADH. Complete reactions also contain CB1954 at a $10 \mu \mathrm{M}$ concentration. All data points represent at least three repeats and error bars indicate \pm 1 standard deviation.

\subsection{Darkfield Imaging}

Enhanced darkfield imaging was performed on SK-OV-3 cells treated with either: Dulbecco's modified eagle medium (DMEM), AuMNP, AuMNP:NfnB-Cys, or AuMNP:NfnB-Cys:HR9, with the HR9 at a 1:1 ratio with the AuMNP. Treatments were done to assess cell uptake of the nanoparticle/nanoparticle conjugates and if the addition of the HR9 aided in increasing cellular uptake. On the basis that the HR9 conjugates appeared to be superior in cell culture testing as an isolated conjugate, only the NfnB-Cys:HR9 combination was progressed to AuMNP testing. Figure 7 is the enhanced darkfield imaging of these slides, Figure 7A is the imaging of cells treated with just DMEM to act as a control, with the cell nucleus stained blue with DAPI. The untreated control cell (panel A) acts as a negative in relation to AuNP internalisation, to which any changes in terms of particle intensity are compared following treatment with AuMNPs. Figure 7B-D are images taken of cells treated with AuMNP, AuMNP:NfnB-Cys, or AuMNP:NfnB-Cys: HR9 respectively, again the cell nuclei are counterstained blue with DAPI. These images have a higher frequency of intense areas within the cells, which are absent when compared to control cells, potentially representing the presence of AuMNPs within the cells. The increased bright areas within the cells in the images indicate that the AuMNPs have internalized into the SK-OV-3 cells and when conjugated with NfnB-Cys, has an increase in internalized nanoparticles. However, the AuMNP has a significant enhancement in nanoparticle internalization when conjugated with a CPP, shown in Figure 7D. 


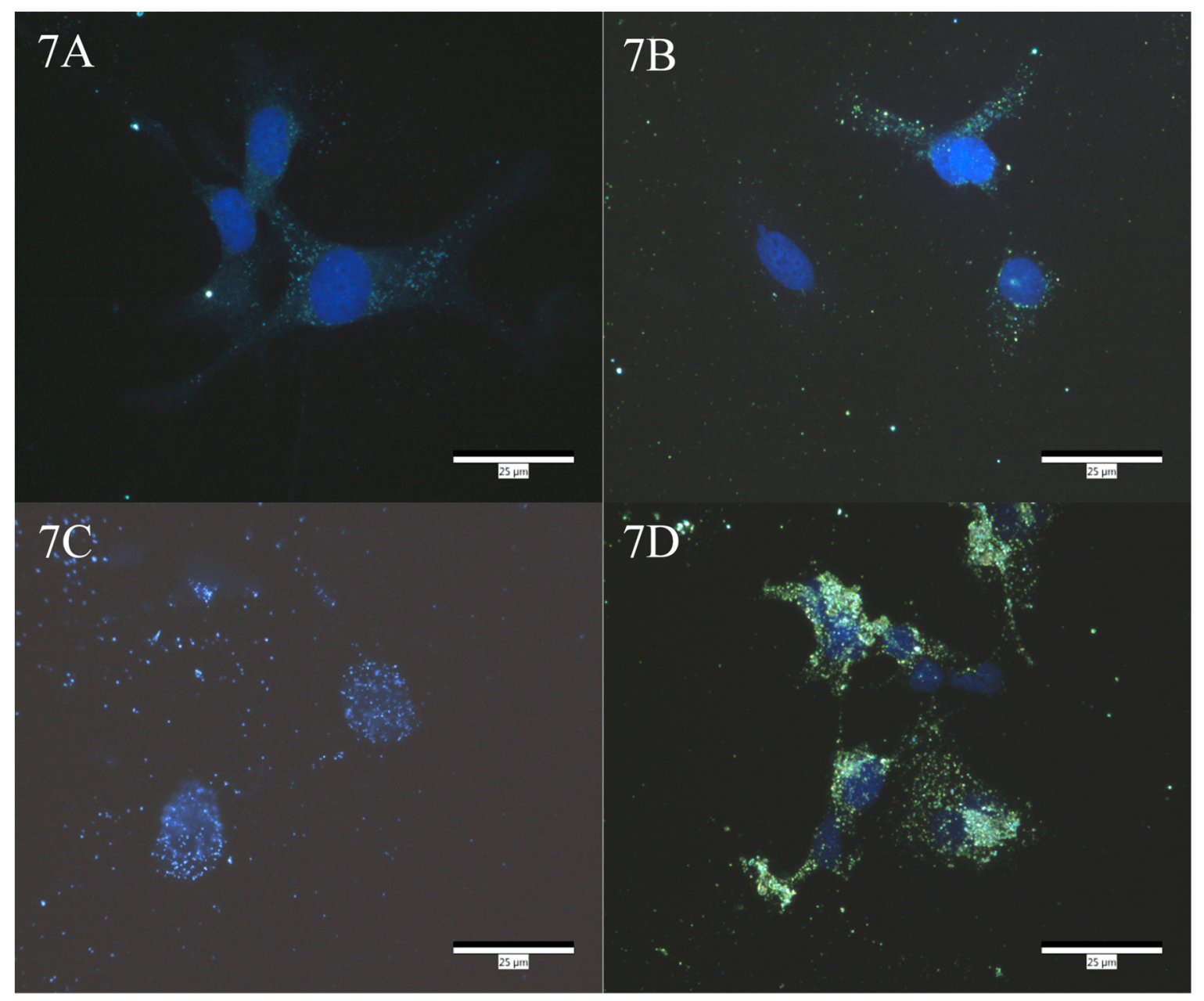

Figure 7. Enhanced darkfield imaging of cells treated with either: Dulbecco's modified eagle medium (DMEM), AuMNP, AuMNP:NfnB-Cys, or AuMNP:NfnB-Cys:HR9, with the images for each presented in (A), (B), (C), and (D) respectively. The cells were treated with DAPI as a co-stain for imaging of the cell nucleus. The scale bar is $25 \mu \mathrm{m}$.

\section{Discussion}

Since their initial discovery in 1988, CPPs have presented as a unique tool for aiding in the uptake and delivery of a range of cargoes for medical applications. Literature shows that CPPs bind non-covalently to specific cargo [36,42-44], the initial work was to determine whether HR9 and Pep-1 could also non-covalently conjugate with our enzyme as a majority of other studies focus on conjugation with inorganic substances such as quantum dots. Conjugation success was confirmed, showing that both HR9 and Pep-1 conjugates significantly alter the electrophoretic migration of NfnB-Cys through the gel (Figure 2A,B) [45]. The HR9 peptide had a greater influence on NfnB-Cys migration, compared to Pep-1, possibly a result of possessing a greater positive charge, caused by the large number of cationic arginine residues [44], nine of which are found in the HR9 CPP [36,46], compared with the one arginine residue found within the Pep-1 [46].

The high positive charges that CPPs possess could present a possible problem in terms of interactions with the physical structure of proteins, this becomes a potential issue for enzyme conjugation as it has previously been established that changes to the physical structure of the NfnB enzyme can cause a change in the product ratio formed when the enzyme is reacted with the CB1954 prodrug [28]. Analysis by HPLC of the product ratio formed for the NfnB-Cys:CPP conjugates showed little to no change from the free NfnB-Cys enzyme (ratio 32:68). NfnB-Cys:HR9 produced a ratio of 36:64, whilst NfnB-Cys:Pep-1 produced a ratio of 35:65. The fact that the CPPs do not heavily 
influence the product ratio formed here indicates that the CPPs are not causing any major alteration to the physical structure of the NfnB-Cys enzyme when they conjugate with it. This is important as it means that the enzyme can still convert the CB1954 into its pharmaceutically active form without CPP interference. A concern that would limit the efficacy of this treatment is that the CPPs are non-covalently bound with the AuMNP:NfnB-Cys conjugate, which could dissociate when introduced to a patient. Stability studies were carried out on AuMNP:NfnB-Cys:CPP conjugates (data not shown) in the cell culture media used in the experiments discussed in this paper. The conjugates were left at $37^{\circ} \mathrm{C}$ to simulate physiological conditions and were stable at up to and including $120 \mathrm{~h}$ which would be a semi-realistic representation of treatment time.

As seen from the HPLC experiment, conjugated CPPs had no real effect on the product ratio of NfnB-Cys, however, establishing if CPP conjugation caused an alteration in enzyme kinetics was essential before progressing. As mentioned in Section 2.3, only the efficiency constant $\left(\mathrm{k}_{\mathrm{cat}} / \mathrm{K}_{\mathrm{m}} \mu \mathrm{M}^{-1} \mathrm{~s}^{-1}\right)$ can be directly compared between the free and conjugated NfnB-Cys. When looking at the $\mathrm{K}_{\mathrm{cat}} / \mathrm{K}_{\mathrm{m}}$ of the free NfnB-Cys, a value of $0.018 \mu \mathrm{M}^{-1} \mathrm{~s}^{-1}$ has previously been reported [29]. Both the $\mathrm{k}_{\text {cat }} / \mathrm{K}_{\mathrm{m}}$ values for the NfnB-Cys:CPP conjugates show a significant drop in their efficiency, with NfnB-Cys:HR9 having a value of $0.0026 \mu \mathrm{M}^{-1} \mathrm{~s}^{-1}$ which is 4-fold less than NfnB-Cys and NfnB-Cys:Pep-1 having a $\mathrm{k}_{\mathrm{cat}} / \mathrm{K}_{\mathrm{m}}$ of $0.0035 \mu \mathrm{M}^{-1} \mathrm{~s}^{-1}$, a value almost 3-fold lower than NfnB-Cys. Therefore, while the earlier experiments showed very little change in both product ratio and product formation, the efficiency of both conjugates and product turnover has dramatically reduced compared to free NfnB-Cys. It is likely that the change in enzymatic efficacy is not detected in the earlier experiments as UV-Vis absorbance measurements were collected at $15 \mathrm{~min}$, and the HPLC reaction time point was $30 \mathrm{~min}$. However, enzymatic kinetic experiments captured a short time frame, calculated over a $20 \mathrm{~s}$ time period. It is likely that whilst the shorter kinetic experiments represent an accurate kinetic picture of the enzyme, the longer experiments possibly indicate a more realistic scenario of the final concentration of products produced as it allows for full reduction and consumption of prodrug. This drastic change in efficiency of the conjugate compared to the free NfnB-Cys does raise a question that requires further research to understand: If the HPLC indicates that the ratio of products formed does not largely differ from the ratio formed by the free NfnB-Cys why does the kinetic data show such a difference? This might indicate that the CPPs have some sort of interaction with the active site of the NfnB-Cys, it may be that there is some slight blockage of the active site, or the CPPs cause a delay in the release of the products from the active site. Further experiments are needed to answer this anomaly in the data.

When examining the NfnB-Cys:CPP conjugates in cell viability assays, there is an observable improvement in the ability of the NfnB-Cys:CPP conjugates to induce cell death over free NfnB-Cys. No additional $\mathrm{NAD}(\mathrm{P}) \mathrm{H}$ was added during the experiments, this was done so that the only cofactor available for the enzyme would be found intracellularly within the SK-OV-3, meaning that the enzyme has to be internalized along with the CB1954 to reduce the prodrug. This increased cell death, and indicates that the addition of CPPs onto the enzyme aids the uptake of the enzyme, allowing the increased cell kill despite the lowered enzymatic efficiency observed. The lower concentration range of NfnB-Cys:HR9 tested in cell culture presents a low cell viability, this can be potentially attributed to the hormetic effect [47], and may indicate a treatment concentration of $25 \mathrm{nM} \mathrm{NfnB-Cys:HR9} \mathrm{as} \mathrm{a}$ better option compared to the $200 \mathrm{nM}$ treatment concentration.

The NfnB-Cys is intended for use in our patented MNDEPT [27], so in order to assess cellular uptake of the enzyme, it was covalently conjugated to the AuMNPs and assessed for its viability as a delivery vector, further conjugating HR9 with the AuMNP:NfnB-Cys and measuring the ability to cause cell death. The cell viability results of the AuMNP trials presented in Figure 6 indicate that the AuMNPs and the AuMNP conjugates do not themselves have an adverse toxic effect on the SK-OV-3 cells, from this it can be reasoned that any cell kill present is from the AuMNPs/AuMNP conjugates that are able to internalize into the cells along with CB1954. Both of the conjugates tested were able to reduce CB1954, shown by the decrease in cell viability which became more pronounced with the increasing concentration dose. 
At each concentration tested, the conjugate with HR9 attached does show an increase in the cell kill. However, this increase is very small, at a maximum $5-10 \%$. This may indicate that either the ratio of HR9 used for the treatment needs to be increased to achieve a higher internalization rate of conjugates. It can also indicate that HR9 is not able to effectively internalize the AuMNP, meaning a different CPP might present as a better option. It is also possible that all the cell culture data has varying degrees of endosomal trapping, preventing the enzyme from fully reducing the prodrug within the cells, in which case the CPPs may need slight modification to achieve endosomal escape either with the use of an endosomolytic agent or a way to reverse high-affinity binding to cell receptors [48]. Furthermore, uptake efficiency of CPPs into cells can vary based on cell type, here the cell line SK-OV-3 showed CPP uptake, however it must be considered that other cell types may show much more limited uptake or no uptake at all. Along with this further work to be done would involve examining the potential lysosomal trapping and to assess colocalization of the nanoparticle conjugates within the cellular structures.

Darkfield imaging was performed on the three nanoparticle/nanoparticle conjugates to assess if the conjugation of either the NfnB-Cys and/or the HR9 increases the cellular internalization of the nanoparticle. Darkfield imaging allows us to visually inspect cells, and view nanoparticles that are associated within the cell, here imaging was performed in an attempt to assess what observable change, if any, the addition of a CPP onto the conjugate had on the cellular internalization of the conjugate. It is observable that the addition of the NfnB-Cys onto the AuMNP causes more nanoparticles to internalize into the cells, compared with unconjugated AuMNP. This is important as it shows that even without the CPP, the AuMNP:NfnB-Cys conjugate can penetrate into the cells, reinforcing that AuMNPs are a viable choice for use in MNDEPT. The more notable difference is observed with the incorporation of a $\mathrm{CPP}$ onto the conjugate. This addition allows a drastically larger number of conjugates to internalize into the cells, indicating that the CPP is being successful in its role.

In conclusion, two different CPPs have been successfully conjugated to the genetically modified NfnB-Cys enzyme at a 1:1 ratio. The HPLC reaction profiles of the NfnB-Cys:CPP conjugates have been described, showing a slight change from the 'free' NfnB-Cys enzyme's product ratio. Kinetic profiles have been established for the conjugates at a 1:1 ratio showing a large drop in the conjugate's kinetic efficiency. However, when the conjugates are tested in cell viability assays an increased cell kill is observed, consistent with what would be expected with an increased uptake of the enzyme, whilst the CPPs themselves show no observable toxicity. Cell viability assays were also performed on AuMNP, AuMNP:NfnB-Cys, and AuMNP:NfnB-Cys:HR9 conjugates, and the AuMNPs themselves had no observable toxicity towards the cells whilst the other tested conjugates demonstrated an increasing cell kill with increasing treatment concentration. Finally, darkfield imaging presents an increased internalization of AuMNP conjugated when HR9 is also conjugated with the AuMNP:NfnB-Cys, which is consistent with the increased cell kill seen on the AuMNP:NfnB-Cys:HR9 conjugate.

\section{Materials and Methods}

All chemicals were supplied from Fisher Scientific, UK and Sigma Aldrich, UK unless stated otherwise.

\subsection{Expression and Purification}

An $n f n b$-cys gene that had been previously cloned into the pET28a(+) (Novagen, Merck, UK) expression vector [14], was transformed into an E.coli Rosetta strain B21 DE3 (Novagen, Merck, UK) and the expression and purification of the NfnB-Cys enzyme was carried out as previously described [14]. Briefly, a colony of E. coli Rosetta containing the expression vector (previously confirmed using gel electrophoresis, data not shown) with the $n f n b$-cys gene was added to a Luria-Bertani (LB) inoculant tube $(5 \mathrm{~mL})$ also containing kanamycin $(50 \mu \mathrm{g} / \mathrm{mL})$. This was vortexed at $1500 \mathrm{rpm}$ overnight for $16 \mathrm{~h}$. Following this the inoculant was added to a flask containing LB expression medium $(500 \mathrm{~mL})$ and kanamycin $(50 \mu \mathrm{g} / \mathrm{mL})$. The bacterial medium was left to grow to an optical density 
of $0.6-0.7$ measured at $590 \mathrm{~nm}$, after which expression of protein was induced by the addition of isopropyl- $\beta$ - ${ }^{-}$-thio-galactoside (IPTG) $(2 \mathrm{~mL}, 100 \mathrm{mM})$. After $4 \mathrm{~h}$ of NfnB-Cys expression, the culture was centrifuged ( $9318 \mathrm{rcf}, 10 \mathrm{~min}, 4^{\circ} \mathrm{C}$ ) and cell contents released by firstly suspending the bacterial pellet in imidazole (10 mM, pH 7.2) and then sonicated on ice for $2 \mathrm{~min}$ at $40 \%$ amplitude, using $30 \mathrm{~s}$ bursts. Cell debris was removed by high-speed centrifugation $(44,800 \mathrm{rcf}, 1 \mathrm{~h})$ and the yellow supernatant passed through a metal ion affinity chromatography column using $\mathrm{Ni}^{2+}$, with imidazole as the eluent. NfnB-Cys protein eluted as yellow fractions that were collected and incubated with flavin mononucleotide (FMN) on ice for $1 \mathrm{~h}$ to ensure cofactor saturation. The saturated solution was then subjected to PD10 size exclusion chromatography (SEC) to remove both impurities and any residual imidazole eluent, before the NfnB-Cys enzyme was collected in phosphate buffer (50 mM, pH 7.2). The molecular weight and purity of the protein fractions were assessed using $12 \%$ SDS-PAGE and visualized using Coomassie blue stain. The concentration of the protein was established using the Bradford assay using a standard BSA curve, according to the manufacturer's instructions.

\subsection{CPP Conjugation to NfnB-Cys}

Conjugation of the CPPs, HR9 (CHHHHHHRRRRRRRRRHHHHHHC) and Pep-1 (KETWWETWWTEWSQPKKKRKV), to the NfnB-Cys enzyme was performed as described for conjugation onto quantum dots $(Q D)$ by Liu et al. [36], and replacing the QD with our NfnB-Cys. This was done by mixing the enzyme and CPP in a silinated Eppendorf at various wt:wt ratios (1:0.1, 1:0.2, 1:1, 1:5 1:10, 1:15). The enzyme: CPP mix was then incubated at $37^{\circ} \mathrm{C}$ for $30 \mathrm{~min}$ and assessed for conjugation via agarose gel electrophoresis.

\subsection{Confirmation of CPP Conjugation to NfnB-Cys}

A $1 \%(\mathrm{w} / \mathrm{v})$ agarose gel was prepared by dissolving agarose $(1 \mathrm{~g})$ in $100 \mathrm{~mL}$ TBE buffer (Tris-HCl; $54 \mathrm{~g}$, Boric acid; $27.5 \mathrm{~g}$, EDTA; $20 \mathrm{~mL}, 500 \mathrm{mM}$ dissolved in $\mathrm{H}_{2} \mathrm{O} 1 \mathrm{~L}, \mathrm{pH}$ 8) [14]. The gel was then submerged in $1 \times$ TBE running buffer and the comb removed. NfnB-Cys:CPP conjugate $(20 \mu \mathrm{L})$ was mixed with $20 \mu \mathrm{L}$ of a $2 \times$ loading dye $(10 \mathrm{mM}$ Tris-HCl pH 6.8, 2\% SDS, $0.01 \%$ Bromophenol blue, $20 \%$ glycerol) [45,49] and loaded onto the gel. Unconjugated NfnB-Cys and CPP were used as controls. The gel was then run at $100 \mathrm{~V}$ for $1 \mathrm{~h}$, and visualized using Coomassie blue stain.

\subsection{NfnB-Cys and NfnB-Cys:CPP Conjugate Activity to CB1954}

NfnB-Cys:CPP conjugates and unconjugated NfnB-Cys were assessed for their reactivity to CB1954 by incubating NfnB-Cys $(25 \mu \mathrm{g} / \mathrm{mL})$ or NfnB-Cys:CPP $(25 \mu \mathrm{g} / \mathrm{mL}$, with volume added adjusted for additional CPP in the mixture to ensure $25 \mathrm{mg} / \mathrm{mL}$ of NfnB-Cys) with NADH (300 $\mu \mathrm{M})$, phosphate buffer $(P B)(50 \mathrm{mM}, \mathrm{pH} 7.2)$, and CB1954 $(100 \mu \mathrm{M})$. Absorbance spectra (200-800 nm) were measured every $90 \mathrm{~s}$ for $15 \mathrm{~min}$ on a Jasco V-550, UV-vis spectrophotometer. Standard control scans were also run on the NADH, enzyme, enzyme:CPP conjugate, prodrug, and CPP with NADH and CB1954 to ensure the CPPs could not reduce the prodrug.

\subsection{CB1954 Kinetics}

CB1954 kinetic experiments were all carried out in a 96-well microtiter plate (Corning, USA) using a Thermoscientific Varioskan 96-well plate microplate reader [29]. Product formation at $420 \mathrm{~nm}$ was measured over time in order to determine the Michaelis-Menten kinetic parameters of CB1954 against the NfnB-Cys:CPP conjugate. CB1954 (0.1-5 mM), NADH $(400 \mu \mathrm{M})$ and PB (50 mM, pH 7.2) were combined and incubated at $37^{\circ} \mathrm{C}$ for 3 min before purified NfnB-Cys or NfnB-Cys:CPP (1:1 ratio) was added $(50 \mu \mathrm{g} / \mathrm{mL}$; again NfnB-Cys:CPP volume added was adjusted to ensure $50 \mu \mathrm{g} / \mathrm{mL}$ of NfnB-Cys was added). Dimethyl sulfoxide (DMSO) solvent concentration was kept constant at $5 \% \mathrm{v} / \mathrm{v}$ to account for any negative solvent related effect [50]. Hydroxylamine yield per second was determined by calculating the change in absorbance over $20 \mathrm{~s}$ and the molar extinction coefficient, which is the same for both products $\left(\varepsilon=1200 \mathrm{M}^{-1} \mathrm{~cm}^{-1}\right.$ at $\left.420 \mathrm{~nm}\right)[14,18,39,50-53]$. Data gathered was transferred to 
SigmaPlot 12 (SPSS, Systat Software Inc.) where a non-linear regression tool was used to generate a Michaelis-Menten hyperbolic curve and a report containing the kinetic information of the system.

\subsection{HPLC}

For HPLC analysis, a Dionex Ultimate 3000 HPLC machine Thermoscientific, USA was used with a C18 column (Waters Spherisorb®5 $\mu \mathrm{m}$ ODS2 $4.6 \mathrm{~mm} \times 250 \mathrm{~mm}$ C18 column, UK). Experiments were carried out at the following parameters: $50 \mu \mathrm{L}$ injection volume, $25^{\circ} \mathrm{C}$ column oven temperature, UV detection wavelength of $420 \mathrm{~nm}$, and a run time of $30 \mathrm{~min}$ [41,42].

HPLC samples were prepared as previously described [29,39]. Briefly, samples were prepared in a $15 \mathrm{~mL}$ amber falcon tube (due to the light-sensitive nature of some of the reaction constituents) as follows: NADH (120 $\mu \mathrm{L}, 10 \mathrm{mM}) \mathrm{NfnB}-\mathrm{Cys} / \mathrm{NfnB}-\mathrm{Cys}: \mathrm{CPP}(116 \mu \mathrm{g} / \mathrm{mL}$, volume adjusted), CB1954 $(20 \mu \mathrm{L}, 50 \mathrm{mM})$ then made to a final volume of $1080 \mu \mathrm{L}$ using PB $(50 \mathrm{mM}, \mathrm{pH}$ 7.2). This mixture was incubated at $25^{\circ} \mathrm{C}$ for $15 \mathrm{~min}$, and then degassed under nitrogen (g) for $15 \mathrm{~min}$, giving a total reaction time of $30 \mathrm{~min}$. Next, $750 \mu \mathrm{L}$ of the final de-gassed reaction was transferred to a chromacol select $2 \mathrm{~mL}$ vial (2-SVW8-CPK) and placed into the HPLC machine. The solvent mixture was acetonitrile/water at a 10:90 ratio, with the acetonitrile increasing at $1 \%$ per $\mathrm{min}$. After $20 \mathrm{~min}$, the acetonitrile concentration was altered to keep increasing by $40 \%$ per minute which reached a concentration of $100 \%$ acetonitrile after $22 \mathrm{~min}$. Eluents were scanned at $420 \mathrm{~nm}$ with product peaks being identified against reagent standards carried out using the same protocol: CB1954 $(20 \mu \mathrm{L}, 50 \mathrm{mM}), \mathrm{NADH}(120 \mu \mathrm{L}, 10 \mathrm{mM})$, and NfnB-Cys $(116 \mu \mathrm{g} / \mathrm{mL}$, volume adjusted for concentration of NfnB-Cys from purification). Ratios of the $2^{\prime}$ and $4^{\prime}$-hydroxylamine products were determined at $420 \mathrm{~nm}$, where both products have equal absorbance [18].

\subsection{Cell Viability Assays}

Cell viability assays were performed as previously described [30]. SK-OV-3 (ECACC 91091004) cells were seeded into a 96-well plate (Corning, USA) at a density of $1 \times 10^{3}$ cells per well, in $100 \mu \mathrm{L}$ Dulbecco's modified eagle medium (DMEM) containing 10\% FBS, $1 \%$ L-glutamine, and $1 \%$ penicillin-streptomycin and allowed to attach to the plate overnight in a $\mathrm{CO}_{2}(5 \%)$ incubator at $37^{\circ} \mathrm{C}$. After $16 \mathrm{~h}$, the media was carefully aspirated off and fresh media containing increasing concentrations of 25 to $200 \mathrm{nM}$ of NfnB-Cys or NfnB-Cys:CPP conjugate $(50 \mu \mathrm{L})$ was added to the wells along with CB1954 $(100 \mu \mathrm{M})$. Wells where only NfnB-Cys, NfnB-Cys:CPP conjugate (200 nM), CB1954 $(10 \mu \mathrm{M})$ or DMEM $(100 \mu \mathrm{L})$ were added served as controls. After a $4 \mathrm{~h}$ incubation in a $\mathrm{CO}_{2}(5 \%)$ incubator at $37^{\circ} \mathrm{C}$, the treatment media was carefully aspirated off and fresh media $(100 \mu \mathrm{L})$ added. Cells were then left for $48 \mathrm{~h}$ in a $\mathrm{CO}_{2}(5 \%)$ incubator at $37^{\circ} \mathrm{C}$, after which MTT (3-(4,5-dimethylthiazol-2-yl)-2,5-diphenyltetrazolium bromide) $(20 \mu \mathrm{L}, 5 \mathrm{mg} / \mathrm{mL})$ was added and then left for a further for $4 \mathrm{~h}$ at $37^{\circ} \mathrm{C}$. Culture media was aspirated off and DMSO $(100 \mu \mathrm{L})$ used to dissolve the purple formazan crystals. Finally, absorbance was read at $570 \mathrm{~nm}$ using a Thermoscientific Varioskan Flash plate reader.

\subsection{Preparation of AuMNP:NfnB-Cys and AuMNP:NfnB-Cys:HR9 Conjugates for Cell Culture and Darkfield Imaging}

Previously synthesised AuMNPs [54] were conjugated with NfnB-Cys following the published method for conjugating NfnB-Cys onto gold nanoparticles [14]. Briefly, magnetically purified, $50 \mathrm{~nm}$ AuMNPs suspended in sodium citrate dehydrate $(1 \mathrm{mM}, \mathrm{pH} 7.4)$ were incubated with a volume of NfnB-Cys at a ratio of 1 AuMNP:270 NfnB-Cys to achieve a monolayer coating of the nanoparticles. The volume of NfnB-Cys incubated with AuMNPs was determined based upon the concentration of NfnB-Cys determined by the Bradford assay and the concentration and size of AuMNPs as determined by UV-Vis [14]. Nano-conjugates were left to form at $4{ }^{\circ} \mathrm{C}$ for $48 \mathrm{~h}$. A full wavelength UV-Vis scan (450-650 nm) was performed on AuMNPs before and after conjugation, with a change in the gold peak being examined for. A redshift of $3-5 \mathrm{~nm}$ of the $\lambda$-max of the gold peak indicates 
successful conjugation [14,55]. AuMNP:NfnB-Cys:HR9 conjugates were prepared by incubating the AuMNP:NfnB-Cys with HR9 at a 1:1 ratio of HR9 to AuMNP, at $37^{\circ} \mathrm{C}$ for $30 \mathrm{~min}$.

\subsection{AuMNP Cell Viability Assays}

The calcein assay was performed with AuMNPs and AuMNP conjugates. SK-OV-3 (ECACC 91091004) cells were seeded into a 96-well plate (Corning, USA) at a density of $1 \times 10^{3}$ cells per well, in $100 \mu \mathrm{L}$ Dulbecco's modified eagle medium (DMEM) containing 10\% FBS, 1\% L-glutamine, and $1 \%$ penicillin-streptomycin and allowed to attach to the plate overnight in a $\mathrm{CO}_{2}(5 \%)$ incubator at $37^{\circ} \mathrm{C}$. After $16 \mathrm{~h}$, the media was carefully aspirated off and fresh media containing increasing concentrations of 25 to $200 \mathrm{nM}$ of AuMNPs, AuMNP:NfnB-Cys, or AuMNP:NfnB-Cys:HR9 $(50 \mu \mathrm{L})$ was added to the wells along with CB1954 $(100 \mu \mathrm{M})$. Wells where only AuMNP, AuMNP:NfnB-Cys AuMNP:NfnB-Cys:CPP conjugate (200 nM), CB1954 $(10 \mu \mathrm{M})$, or DMEM $(100 \mu \mathrm{L})$ were added served as controls. After a $4 \mathrm{~h}$ incubation in a $\mathrm{CO}_{2}(5 \%)$ incubator at $37^{\circ} \mathrm{C}$, the treatment media was carefully aspirated off and fresh media $(100 \mu \mathrm{L})$ added. Cells were then left for $48 \mathrm{~h}$ in a $\mathrm{CO}_{2}(5 \%)$ incubator at $37^{\circ} \mathrm{C}$, after which the media was carefully aspirated off and $1 \times$ calcein DW buffer $(100 \mu \mathrm{L})$ was added to each well. This was again carefully aspirated off after which $1 \times$ calcein DW buffer $(50 \mu \mathrm{L})$ and $2 \times$ calcein AM $(50 \mu \mathrm{L})$ were added to each well. The plate was then incubated for $30 \mathrm{~min}$ in a $\mathrm{CO}_{2}$ $(5 \%)$ incubator at $37^{\circ} \mathrm{C}$. The fluorescence of the sample was measured using an excitation/emission filter of 495/515 nm using a Thermoscientific Varioskan Flash plate reader.

\subsection{Darkfield Imaging}

Darkfield imaging was performed using CytoViva enhanced darkfield imaging. SK-OV-3 cells were seeded onto 8-well Thermo Scientific ${ }^{\mathrm{TM}} \mathrm{Nunc}^{\mathrm{TM}}$ Lab-Tek $^{\mathrm{TM}}$ II Chamber Slide\&trade glass slides at a density of $1 \times 10^{4}$ cells per well. Sub-confluent cells $(\sim 80 \%)$ were treated with either DMEM media as a control, unconjugated/'naked' AuMNPs, AuMNP conjugated with NfnB-Cys at a ratio of 1:270 of AuMNP:NfnB-Cys, or AuMNP:NfnB-Cys conjugated with HR9, with the CPP conjugated at a ratio of 1:1 with the AuMNP:NfnB-Cys conjugates. Cells were incubated with complexes for $4 \mathrm{~h}$ before the treatment media was removed and cells washed twice with DPBS, removing loosely associated external nanoparticles [56-60]. Cells were then fixed using 3.7\% formaldehyde and mounted using Vectashield containing 4',6-diamidino-2-phenylindole (DAPI) (Vector labs), counterstaining the nucleus.

Author Contributions: Conceptualization, C.D.G.; methodology, S.D.A. and R.J.H; validation, S.D.A., R.J.H., and C.D.G.; formal analysis, S.D.A.; investigation, S.D.A., L.A.B., V.V.G., and P.B.; resources, C.D.G. and J.A.C.; data curation, S.D.A.; writing—original draft preparation, S.D.A.; writing—review and editing, S.D.A, R.J.H., V.V.G. and C.D.G.; visualization, S.D.A.; supervision, C.D.G.; project administration, C.D.G.; funding acquisition, C.D.G.

Funding: This research was funded by the Life Sciences Research Network Wales (LSRNW), the Knowledge Economy Skills Scholarship (KESS), and Cancer Research Wales (CRW).

Acknowledgments: The authors would like to thank the School of Pharmacy at Queens University Belfast and the School of Natural Sciences at Bangor University for their support throughout this project.

Conflicts of Interest: The authors declare no conflict of interest.

\section{References}

1. Guo, P.; Coban, O.; Snead, N.M.; Trebley, J.; Hoeprich, S.; Guo, S.; Shu, Y. Engineering rna for targeted sirna delivery and medical application. Adv. Drug Deliv. Rev. 2010, 62, 650-666. [CrossRef] [PubMed]

2. Doherty, G.J.; McMahon, H.T. Mechanisms of endocytosis. Annu. Rev. Biochem. 2009, 78, 857-902. [CrossRef] [PubMed]

3. Luzio, J.P.; Poupon, V.; Lindsay, M.R.; Mullock, B.M.; Piper, R.C.; Pryor, P.R. Membrane dynamics and the biogenesis of lysosomes. Mol. Membr. Biol. 2003, 20, 141-154. [CrossRef] [PubMed]

4. Mukherjee, S.; Ghosh, R.N.; Maxfield, F.R. Endocytosis. Physiol. Rev. 1997, 77, 759-803. [CrossRef] [PubMed]

5. Trabulo, S.; Cardoso, A.L.; Mano, M.; de Lima, M.C.P. Cell-penetrating peptides-mechanisms of cellular uptake and generation of delivery systems. Pharmaceuticals 2010, 3, 961-993. [CrossRef] [PubMed] 
6. Madani, F.; Lindberg, S.; Langel, Ü.; Futaki, S.; Gräslund, A. Mechanisms of cellular uptake of cell-penetrating peptides. J. Biophys. 2011, 2011, 1-10. [CrossRef]

7. Langel, Ü. Handbook of Cell Penetrating Peptides, 2nd ed.; Taylor \& Francis Group, LLC: Oxford, UK, 2006; Volume 28, ISBN 9780849350900.

8. Rothbard, J.B.; Jessop, T.C.; Lewis, R.S.; Murray, B.A.; Wender, P.A. Role of Membrane Potential and Hydrogen Bonding in the Mechanism of Translocation of Guanidinium-Rich Peptides into Cells. J. Am. Chem. Soc. 2004, 126, 9506-9507. [CrossRef]

9. Mitchell, D.J.; Steinman, L.; Kim, D.T.; Fathman, C.G.; Rothbard, J.B. Polyarginine enters cells more efficiently than other polycationic homopolymers. J. Pept. Res. 2000, 56, 318-325. [CrossRef]

10. Järver, P.; Langel, Ü. Cell-penetrating peptides-A brief introduction. Biochim. Biophys. Acta Biomembr. 2006, 1758, 260-263. [CrossRef]

11. Kato, T.; Yamashita, H.; Misawa, T.; Nishida, K.; Kurihara, M.; Tanaka, M.; Demizu, Y.; Oba, M. Plasmid DNA delivery by arginine-rich cell-penetrating peptides containing unnatural amino acids. Bioorg. Med. Chem. 2016, 24, 2681-2687. [CrossRef]

12. Gautam, A.; Nanda, J.S.; Samuel, J.S.; Kumari, M.; Priyanka, P.; Bedi, G.; Nath, S.K.; Mittal, G.; Khatri, N.; Raghava, G.P.S. Topical Delivery of Protein and Peptide Using Novel Cell Penetrating Peptide IMT-P8. Sci. Rep. 2016, 6, 26278. [CrossRef] [PubMed]

13. Asai, T.; Tsuzuku, T.; Takahashi, S.; Okamoto, A.; Dewa, T.; Nango, M.; Hyodo, K.; Ishihara, H.; Kikuchi, H.; Oku, N. Cell-penetrating peptide-conjugated lipid nanoparticles for siRNA delivery. Biochem. Biophys. Res. Commun. 2014, 444, 599-604. [CrossRef] [PubMed]

14. Gwenin, V.V.; Gwenin, C.D.; Kalaji, M. Colloidal gold modified with a genetically engineered nitroreductase: Toward a novel enzyme delivery system for cancer prodrug therapy. Langmuir 2011, 27, 14300-14307. [CrossRef] [PubMed]

15. Zhang, J.; Kale, V.; Chen, M. Gene-Directed Enzyme Prodrug Therapy. AAPS J. 2015, 17, 102-110. [CrossRef]

16. Knox, R.J.; Friedlos, F.; Boland, M.P. The bioactivation of CB 1954 and its use as a prodrug in antibody-directed enzyme prodrug therapy (ADEPT). Cancer Metastasis Rev. 1993, 12, 195-212. [CrossRef]

17. Williams, E.M.; Little, R.F.; Mowday, A.M.; Rich, M.H.; Chan-Hyams, J.V.E.; Copp, J.N.; Smaill, J.B.; Patterson, A.V.; Ackerley, D.F. Nitroreductase gene-directed enzyme prodrug therapy: Insights and advances toward clinical utility. Biochem. J. 2015, 471, 131-153. [CrossRef]

18. Race, P.R.; Lovering, A.L.; White, S.A.; Grove, J.I.; Searle, P.F.; Wrighton, C.W.; Hyde, E. Kinetic and Structural Characterisation of Escherichia coli Nitroreductase Mutants Showing Improved Efficacy for the Prodrug Substrate CB1954. J. Mol. Biol. 2007, 368, 481-492. [CrossRef]

19. Knox, R.J.; Friedlos, F.; Sherwood, R.F.; Melton, R.G.; Anlezark, G.M. The bioactivation of 5-(aziridin-1-yl)-2,4-dinitrobenzamide (CB1954)-II. A comparison of an Escherichia coli nitroreductase and Walker DT diaphorase. Biochem. Pharmacol. 1992, 44, 2297-2301. [CrossRef]

20. Helsby, N.A.; Ferry, D.M.; Patterson, A.V.; Pullen, S.M.; Wilson, W.R. 2-Amino metabolites are key mediators of CB 1954 and SN 23862 bystander effects in nitroreductase GDEPT. Br. J. Cancer 2004, 90, 1084-1092. [CrossRef]

21. Patel, P.; Young, J.G.; Mautner, V.; Ashdown, D.; Bonney, S.; Pineda, R.G.; Collins, S.I.; Searle, P.F.; Hull, D.; Peers, E.; et al. A phase I/II clinical trial in localized prostate cancer of an adenovirus expressing nitroreductase with CB1984. Mol. Ther. 2009, 17, 1292-1299. [CrossRef]

22. Schepelmann, S.; Springer, C.J. Viral vectors for gene-directed enzyme prodrug therapy. Curr. Gene Ther. 2006, 6, 647-670. [CrossRef] [PubMed]

23. Palmer, D.H.; Mautner, V.; Mirza, D.; Oliff, S.; Gerritsen, W.; Van der Sijp, J.R.M.; Hubscher, S.; Reynolds, G.; Bonney, S.; Rajaratnam, R.; et al. Virus-directed enzyme prodrug therapy: Intratumoral administration of a replication-deficient adenovirus encoding nitroreductase to patients with resectable liver cancer. J. Clin. Oncol. 2004, 22, 1546-1552. [CrossRef] [PubMed]

24. Bagshawe, K.D. Antibody-Directed Enzyme Prodrug Therapy Professor. In Prodrugs: Challenges and rewards; Valentino, S., Borchardt, R., Hageman, M., Oliyai, R., Maag, H., Jefferson, T.W., Eds.; Springer: New York, NY, USA, 2005; pp. 526-536. ISBN 978-0-387-49785-3.

25. Wadhwa, M.S.; Collard, W.T.; Adami, R.C.; McKenzie, D.L.; Rice, K.G. Peptide-mediated gene delivery: Influence of peptide structure on gene expression. Bioconjug. Chem. 1997, 8, 81-88. [CrossRef] [PubMed] 
26. Behr, J.P. Gene Transfer with Synthetic Cationic Amphiphiles: Prospects for Gene Therapy. Bioconjug. Chem. 1994, 5, 382-389. [CrossRef]

27. Gwenin, V.V.; Gwenin, C.D.; Kalaji, M. Drug Activation Carrier. European Union Patent EP2473197-A2, 2009.

28. Gwenin, C.D.; Kalaji, M.; Williams, P.A.; Jones, R.M. The orientationally controlled assembly of genetically modified enzymes in an amperometric biosensor. Biosens. Bioelectron. 2007, 22, 2869-2875. [CrossRef]

29. Ball, P.; Thompson, E.; Anderson, S.; Gwenin, V.; Gwenin, C. Time dependent HPLC analysis of the product ratio of enzymatically reduced prodrug CB1954 by a modified and immobilised nitroreductase. Eur. J. Pharm. Sci. 2019, 127, 217-224. [CrossRef]

30. Liu, B.R.; Liou, J.S.; Chen, Y.J.; Huang, Y.W.; Lee, H.J. Delivery of Nucleic Acids, Proteins, and Nanoparticles by Arginine-Rich Cell-Penetrating Peptides in Rotifers. Mar. Biotechnol. 2013, 15, 584-595. [CrossRef]

31. Deshayes, S.; Heitz, A.; Morris, M.C.; Charnet, P.; Divita, G.; Heitz, F. Insight into the Mechanism of Internalization of the Cell-Penetrating Carrier Peptide Pep-1 through Conformational Analysis. Biochemistry 2004, 43, 1449-1457. [CrossRef]

32. Wang, M.H.; Otteson, D.C. Intracellular Delivery of Proteins into Mouse Muller Glia Cells in vitro and in vivo Using Pep-1 Transfection Reagent. J. Neurosci. 2010, 177, 403-419. [CrossRef]

33. Gros, E.; Deshayes, S.; Morris, M.C.; Aldrian-Herrada, G.; Depollier, J.; Heitz, F.; Divita, G. A non-covalent peptide-based strategy for protein and peptide nucleic acid transduction. Biochim. Biophys. Acta Biomembr. 2006, 1758, 384-393. [CrossRef]

34. Koshman, Y.E.; Waters, S.B.; Walker, L.A.; Los, T.; de Tombe, P.; Goldspink, P.H.; Russell, B. Delivery and visualization of proteins conjugated to quantum dots in cardiac myocytes. J. Mol. Cell. Cardiol. 2008, 45, 853-856. [CrossRef] [PubMed]

35. Kurzawa, L.; Pellerano, M.; Morris, M.C. PEP and CADY-mediated delivery of fluorescent peptides and proteins into living cells. Biochim. Biophys. Acta Biomembr. 2010, 1798, 2274-2285. [CrossRef] [PubMed]

36. Liu, B.R.; Huang, Y.W.; Winiarz, J.G.; Chiang, H.J.; Lee, H.J. Intracellular delivery of quantum dots mediated by a histidine- and arginine-rich HR9 cell-penetrating peptide through the direct membrane translocation mechanism. Biomaterials 2011, 32, 3520-3537. [CrossRef] [PubMed]

37. Liu, B.R.; Der Lin, M.; Chiang, H.J.; Lee, H.J. Arginine-rich cell-penetrating peptides deliver gene into living human cells. Gene 2012, 505, 37-45. [CrossRef] [PubMed]

38. Zhang, D.; Wang, J.; Xu, D. Cell-penetrating peptides as noninvasive transmembrane vectors for the development of novel multifunctional drug-delivery systems. J. Control. Release 2016, 229, 130-139. [CrossRef] [PubMed]

39. Gwenin, V.V.; Poornima, P.; Halliwell, J.; Ball, P.; Robinson, G.; Gwenin, C.D. Identification of novel nitroreductases from Bacillus cereus and their interaction with the CB1954 prodrug. Biochem. Pharmacol. 2015, 98, 392-402. [CrossRef] [PubMed]

40. Habtemariam, S. Catechols and quercetin reduce MTT through iron ions: A possible artefact in cell viability assays. Phyther. Res. 1995, 9, 603-605. [CrossRef]

41. Lupu, A.R.; Popescu, T. The noncellular reduction of MTT tetrazolium salt by $\mathrm{TiO}_{2}$ nanoparticles and its implications for cytotoxicity assays. Toxicol. Vitr. 2013, 27, 1445-1450. [CrossRef]

42. Morris, M.C.; Depollier, J.; Mery, J.; Heitz, F.; Divita, G. A peptide carrier for the delivery of biologically active proteins into mammalian cells. Nat. Biotechnol. 2001, 19, 1173-1176. [CrossRef]

43. Morris, M.C.; Gros, E.; Aldrian-Herrada, G.; Choob, M.; Archdeacon, J.; Heitz, F.; Divita, G. A non-covalent peptide-based carrier for in vivo delivery of DNA mimics. Nucleic Acids Res. 2007, 35, 2191-2198. [CrossRef]

44. Morris, M.C.; Deshayes, S.; Heitz, F.; Divita, G. Cell-penetrating peptides: From molecular mechanisms to therapeutics. Biol. Cell 2008, 100, 201-217. [CrossRef] [PubMed]

45. Arndt, C.; Koristka, S.; Bartsch, H.; Bachmann, M. Native Polyacrylamide Gels. Protein Electrophor. Methods Protoc. 2012, 869, 287-304.

46. Liu, B.R.; Li, J.-F.; Lu, S.-W.; Leel, H.-J.; Huang, Y.-W.; Shannon, K.B.; Aronstam, R.S. Cellular internalization of quantum dots noncovalently conjugated with arginine-rich cell-penetrating peptides. J. Nanosci. Nanotechnol. 2010, 10, 6534-6543. [CrossRef] [PubMed]

47. Mattson, M.P. Hormesis defined. Ageing Res. Rev. 2008, 7, 1-7. [CrossRef] [PubMed]

48. LeCher, J.C.; Nowak, S.J.; McMurry, J.L. Breaking in and busting out: Cell-penetrating peptides and the endosomal escape problem. Biomol. Concepts 2017, 8, 131-141. [CrossRef] 
49. Bio-Rad Buffer Formulations. Available online: http://www.bio-rad.com/webroot/web/pdf/lsr/literature/ Bulletin_6199.pdf (accessed on 1 September 2019).

50. Vass, S.O.; Jarrom, D.; Wilson, W.R.; Hyde, E.I.; Searle, P.F.E. coli NfsA: An alternative nitroreductase for prodrug activation gene therapy in combination with CB1954. Br. J. Cancer 2009, 100, 1903-1911. [CrossRef]

51. Swe, P.M.; Copp, J.N.; Green, L.K.; Guise, C.P.; Mowday, A.M.; Smaill, J.B.; Patterson, A.V.; Ackerley, D.F. Targeted mutagenesis of the Vibrio fischeri flavin reductase FRase i to improve activation of the anticancer prodrug CB1954. Biochem. Pharmacol. 2012, 84, 775-783. [CrossRef]

52. Prosser, G.A.; Patterson, A.V.; Ackerley, D.F. UvrB gene deletion enhances SOS chromotest sensitivity for nitroreductases that preferentially generate the 4-hydroxylamine metabolite of the anti-cancer prodrug CB1954. J. Biotechnol. 2010, 150, 190-194. [CrossRef]

53. Prosser, G.A.; Copp, J.N.; Syddall, S.P.; Williams, E.M.; Smaill, J.B.; Wilson, W.R.; Patterson, A.V.; Ackerley, D.F. Discovery and evaluation of Escherichia coli nitroreductases that activate the anti-cancer prodrug CB1954. Biochem. Pharmacol. 2010, 79, 678-687. [CrossRef]

54. Cude, M.P.; Gwenin, C.D. Development of Gold Coated Superparamagnetic Iron Oxide Nanoparticles for Nitroreductase Delivery. ECS Trans. 2011, 33, 79-89.

55. Haiss, W.; Thanh, N.T.K.; Aveyard, J.; Fernig, D.G. Determination of Size and Concentration of Gold Nanoparticles from UV-Vis Spectra Determination of Size and Concentration of Gold Nanoparticles from UV-Vis Spectra. Anal. Chem 2007, 79, 4215-4221. [CrossRef] [PubMed]

56. Kocbek, P.; Cegnar, M.; Kos, J.; Kristl, J. Targeting cancer cells using PLGA nanoparticles surface modified with monoclonal antibody. J. Control. Release 2007, 120, 18-26. [CrossRef] [PubMed]

57. Han, G.; You, C.; Kim, B.; Turingan, R.S.; Forbes, N.S.; Martin, C.T.; Rotello, V.M. Light-Regulated Release of DNA and Its Delivery to Nuclei by Means of Photolabile Gold Nanoparticles **. Angew. Chem. Int. Ed. 2006, 45, 3165-3169. [CrossRef] [PubMed]

58. Gu, Y.; Cheng, J.; Lin, C.; Wah, Y.; Han, S.; Wong, W. Nuclear penetration of surface functionalized gold nanoparticles. Toxicol. Appl. Pharmacol. 2009, 237, 196-204. [CrossRef] [PubMed]

59. Wang, C.; Sun, A.; Qiao, Y.; Zhang, P.; Ma, L.; Su, M. Cation surface modification of gold nanoparticles for enhanced cellular uptake and X-Ray radiation therapy. J. Mater. Chem. B 2015, 3, 7372-7376. [CrossRef]

60. Arnida, M.A.; Ghanderhari, H. Cellular uptake and toxicity of gold nanoparticles in prostate cancer cells: A comparative study of rods and spheres. J. Appl. Toxicol. 2010, 30, 212-217. [CrossRef] 